\title{
Linkages between ENSO/PDO signals and precipitation, streamflow in China during the last 100 years
}

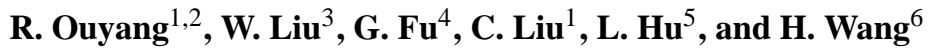 \\ ${ }^{1}$ Key Laboratory of Water Cycle \& Related Land Surface Processes, Institute of Geographic Sciences and Natural Resources \\ Research, Chinese Academy of Sciences, Beijing, 100101, China \\ ${ }^{2}$ Bureau of Comprehensive Development Ministry of Water Resources, Beijing, 100053, China \\ ${ }^{3}$ Key Laboratory of Tibetan Environment Changes and Land Surface Processes, Institute of Tibetan Plateau Research, \\ Chinese Academy of Sciences, Beijing, 100101, China \\ ${ }^{4}$ CSIRO Land and Water, Private Bag 5, Wembley, WA 6913, Australia \\ ${ }^{5}$ Zhejiang Provincial Hydrology Bureau, Hangzhou, 310009, China \\ ${ }^{6}$ Graduate School of INSA, 35000 Rennes, France \\ Correspondence to: W. Liu (liuwb@itpcas.ac.cn)
}

Received: 4 March 2014 - Published in Hydrol. Earth Syst. Sci. Discuss.: 15 April 2014

Revised: 16 July 2014 - Accepted: 12 August 2014 - Published: 17 September 2014

\begin{abstract}
This paper investigates the single and combined impacts of El Niño-Southern Oscillation (ENSO) and the Pacific Decadal Oscillation (PDO) on precipitation and streamflow in China over the last century. Results indicate that the precipitation and streamflow overall decrease during El Niño/PDO warm phase periods and increase during La Niña/PDO cool phase periods in the majority of China, although there are regional and seasonal differences. Precipitation and streamflow in the Yellow River basin, Yangtze River basin and Pearl River basin are more significantly influenced by El Niño and La Niña events than is precipitation and streamflow in the Songhua River basin, especially in October and November. Moreover, significant influence of ENSO on streamflow in the Yangtze River mainly occurs in summer and autumn while in the Pearl River influence primarily occurs in the winter and spring. The precipitation and streamflow are relatively greater in the warm PDO phase in the Songhua River basin and several parts of the Yellow River basin and relatively less in the Pearl River basin and most parts of Northwest China compared to those in the cool PDO phase, though there is little significance detected by Wilcoxon signed-rank test. When considering the combined influence of ENSO and PDO, the responses of precipitation/streamflow are shown to be opposite in northern China and southern China, with ENSO-related precipitation/streamflow enhanced in northern China and decreased
\end{abstract}

in southern China during the warm PDO phases, and enhanced in southern China and decreased in northern China during the cool PDO phases. It is hoped that this study will be beneficial for understanding the precipitation/streamflow responses to the changing climate and will correspondingly provide valuable reference for water resources prediction and management across China.

\section{Introduction}

It is well known that El Niño-Southern Oscillation (ENSO) is an important factor influencing the interannual climate variability over East Asia (Zhou and Wu, 2010). The warm ENSO, which is also called El Niño, is usually accompanied by a weaker than normal East Asian winter monsoon (Zhang et al., 1996; Wang et al., 2008) and consequently induces a warmer and wetter climate over East Asia during El Niño winters (Li, 1990; Wen et al., 2000). As an example, ENSO influences can persist to the following summer, with significantly abundant precipitation and annual maximum streamflow over the Yangtze River valley during the decaying stage of an El Niño event (Huang and Wu, 1989; Zhang et al., 2007). However, the aforementioned anomalies generally reverse during the cool ENSO phase, namely La Niña events (Wang et al., 2008). 
Some previous studies (Latif and Barnett, 1996; Mantua et al., 1997; Cayan et al., 1998; Nigam et al., 1999; Higgins and Shi, 2000; Minobe, 2000; Neal et al., 2002; Krishnan and Sugi, 2003; Wang et al., 2008) have indicated that the interannual relationship between ENSO and global climate is not stationary and that the Pacific Decadal Oscillation (PDO), which is a largely interdecadal oscillation, can modulate the interannual ENSO-related teleconnections. For instance, the already enhanced precipitation and streamflow in eastern Australia have been demonstrated to be even further magnified during La Niña events that occurred in the PDO/IPO (Interdecadal Pacific Oscillation) cool phase (Verdon et al., 2004). Additionally, the precipitation patterns showed different responses in El Niño periods for southeastern South America and Myanmar during PDO warm/cool phases (Silva et al., 2011; Sen Roy and Sen Roy, 2011). These studies indicated that the in-phase/out-of-phase relationships of ENSO and PDO usually have distinct effects on precipitation and streamflow in different regions, and thus, discussions considering the influences of ENSO in association with PDO are necessary.

There are various studies extensively documenting the linkages between ENSO/PDO and annual/seasonal precipitation over China during the past several decades (Liu and Ding, 1995; Gong and Wang, 1999; Zhang et al., 1999; Wu et al., 2003; Zhu and Yang, 2003; Xu et al., 2004; Li et al., 2005; Chan and Zhou, 2005; Ma and Shao, 2006; Hao et al., 2008; Zhou and Wu, 2010). For example, Zhou and $\mathrm{Wu}$ (2010) revealed that warm ENSO mainly led to lowerlevel southwesterly winds being deflected from the southeast coast of China and consequently influencing the winter precipitation in southern China. In addition, Chan and Zhou (2005) found that there was less precipitation over the South China monsoon region during periods of high PDO index and vice versa. However, the majority of the aforementioned studies did not consider the combined influences of both ENSO and PDO on regional precipitation. On the other hand, streamflow, as a comprehensive integrator of rainfall over basin areas, is also related to variations of ENSO and PDO signals. If a strong relationship between river discharge and ENSO/PDO can be quantified, the accuracy of streamflow forecasting, which is vital for effective water resource management, would be greatly improved. Although many studies have now been conducted on the relationship between river streamflow and ENSO/PDO in China (Chen and $\mathrm{Xu}, 2005$; Fu et al., 2007; $\mathrm{Xu}$ et al., 2007; Zhang et al., 2007; Lü et al., 2011), as far as we are aware, there has not been a study documenting the combined influences of both ENSO and PDO signals on streamflow in the major large rivers over China. Considering all of the above, in this paper, the possible influences of ENSO and PDO, coupled and separately, on the annual/monthly precipitation and streamflow over China are considered. Additionally, the precipitation and annual streamflow data sets adopted in this study were extended to the last 100 years (1901-2009) and full seasonal cycles were considered in order to more reliably present climate variability.

The paper is organized as follows. Section 2 introduces the data sets and methodologies used. Section 3 examines the relationships among PDO, ENSO, precipitation and streamflow, and finally, conclusions and proposed future research are presented in Sect. 4.

\section{Data and method}

\subsection{Data}

\subsubsection{The precipitation data}

The precipitation data (1901-2009) in China were extracted from the latest Climatic Research Unit (CRU) Time Series (TS) 3.10 high-resolution gridded data sets (http://badc.nerc.ac.uk/view/badc.nerc.ac.uk_ATOM_ dataent_1256223773328276) at the University of East Anglia (Mitchell and Jones, 2005). The monthly CRU TS3.10 data sets, which were calculated on high-resolution $\left(0.5^{\circ} \times 0.5^{\circ}\right)$ grids based on more than 4000 weather stations distributed around the world (with more than 160 meteorological stations from China), were validated to match well with the observations over China except for the western Tibetan Plateau (Ma and Shao, 2006).

\subsubsection{The streamflow data}

There are only a few streamflow gauging stations that have 100 years' of continuous observational records in China. Therefore, four gauging stations, Harbin Station in Songhua River basin, Shanxian Station (renamed Sanmenxia station in 1950) in Yellow River basin, Hankou Station in Yangtze River basin and Wuzhou Station in Pearl River basin were chosen in this study after considering location, length of observation period and quality of the data observed (Table 1). They are all control stations located on the main channel of the four main rivers of China. The location of the gauging stations and the four river basins can be seen in Fig. 1. Songhua River basin, Yellow River basin, Yangtze River basin and Pearl River basin, being the four major large river basins in China, range approximately from the north to the south of China and cover almost all climate types of China. Songhua River basin is located in the north of northern China and lies in the temperate monsoon climate zone. The Yellow River basin can be divided into three sub-regions (i.e. the eastern monsoon sub-region, the arid and semi-arid sub-region, and the high-elevation sub-region), in accordance with the three natural zones of China (Liang et al., 2014). The southern part of the Yangtze River basin is close to the tropical zone and the northern part is close to the temperate region. The Pearl River basin covers a region of subtropical to tropical monsoon climate straddling the Tropic of Cancer. The selected basins are expected to be able to represent the streamflow 
Table 1. Background information of the four selected river basins in this study.

\begin{tabular}{llrrrrr}
\hline River basin & Station (location) & $\begin{array}{r}\text { Drainage } \\
\text { area } \\
\left(\mathrm{km}^{2}\right)\end{array}$ & $\begin{array}{r}\text { Annual } \\
\text { streamflow } \\
\text { record period }\end{array}$ & $\begin{array}{r}\text { Monthly streamflow } \\
\text { record period }\end{array}$ & $\begin{array}{r}\text { Annual mean } \\
\text { precipitation } \\
\left(\mathrm{mm} \mathrm{yr}^{-1}\right)\end{array}$ & $\begin{array}{r}\text { Annual mean } \\
\text { streamflow } \\
\left(10^{8} \mathrm{~m}^{3} \mathrm{a}^{-1}\right)\end{array}$ \\
\hline Songhua River (I) & Harbin $\left(126^{\circ} 46^{\prime} \mathrm{E}, 45^{\circ} 45^{\prime} \mathrm{N}\right)$ & 390526 & $1901-2009$ & $1901-1948$, & $491(1901-2009)$ & $386(1901-2009)$ \\
& & & & $1953-2004$ & & \\
& & & & & \\
& & & & & \\
Yellow River (II) & Sanmenxia $\left(111^{\circ} 22^{\prime} \mathrm{E}, 34^{\circ} 49^{\prime} \mathrm{N}\right)$ & 688421 & $1901-2009$ & $1901-2009)$ & $489(1901-2009)$ \\
Yellow River (II) & Huayuankou $\left(113^{\circ} 40^{\prime} \mathrm{E}, 34^{\circ} 54^{\prime} \mathrm{N}\right)$ & 730036 & - & $1950-2004$ & $449(1901-2009)$ & $555(1950-2004)$ \\
Yangtze River (III) & Hankou $\left(114^{\circ} 18^{\prime} \mathrm{E}, 30^{\circ} 37^{\prime} \mathrm{N}\right)$ & 1488036 & $1901-2009$ & $1901-2004$ & $887(1901-2009)$ & $7256(1901-2009)$ \\
Pearl River (IV) & Wuzhou $\left(111^{\circ} 30^{\prime} \mathrm{E}, 23^{\circ} 48^{\prime} \mathrm{N}\right)$ & 329705 & $1901-2009$ & $1950-2004$ & $1307(1901-2009)$ & $2175(1901-2009)$ \\
\hline
\end{tabular}

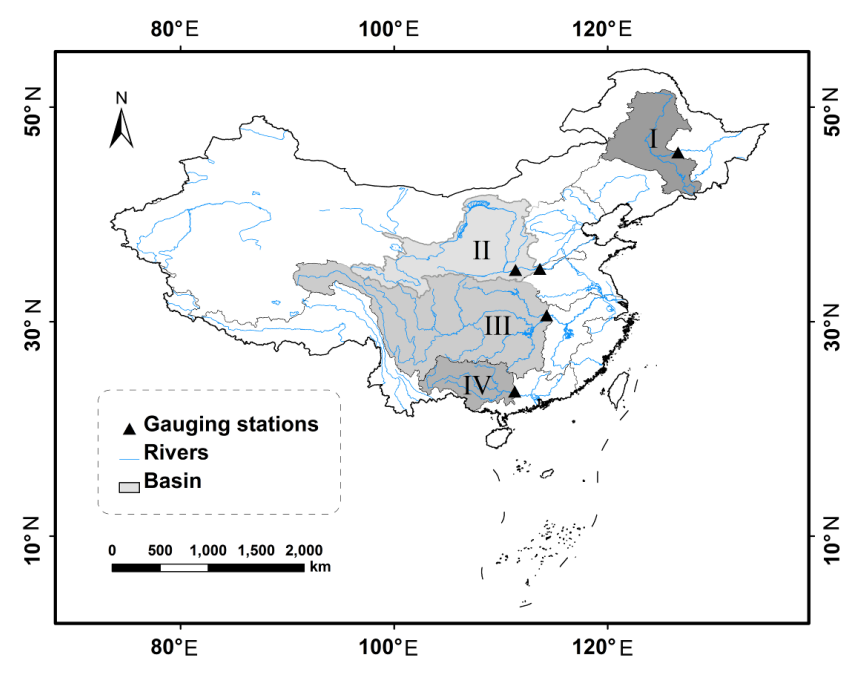

Figure 1. Map of China showing the four major river basins (I: Songhua River basin; II: Yellow River basin; III: Yangtze River basin and IV: Pearl River basin) and streamflow gauging stations used in this study.

variability over China under climate change. In this study, a century (1901-2009) of continuous quality-controlled annual streamflow data and 50-100 years of monthly streamflow data were collected from the National Hydrology Almanac.

\subsubsection{ENSO and PDO}

The ENSO index is represented by the Niño 3.4 SST defined as the January to March SST anomaly averages over the region $\left(5^{\circ} \mathrm{S}-5^{\circ} \mathrm{N}, 90-150^{\circ} \mathrm{W}\right)$, downloaded from the National Oceanic and Atmospheric Administration (NOAA, http://www.cgd.ucar.edu/cas/catalog/climind/ Nino_33.4indices.html) (Trenberth, 1997). The PDO index "is the leading empirical orthogonal function (EOF) of SST anomalies (January to March) in the North Pacific Ocean, poleward of $20^{\circ} \mathrm{N}$ " (Mantua et al., 1997; Chan and Zhou, 2005) and is available at the Joint Institute for the Study of the Atmosphere and Ocean (JISAO) website: http://jisao. washington.edu/pdo/ (Barnett et al., 1999).

\subsection{Method}

\subsubsection{Precipitation and streamflow stratification according to El Niño and La Niña}

ENSO is a quasi-periodic climate pattern that occurs across the tropical Pacific Ocean every several years (3 to 7 years' recurrence) which always couples two variations: the warm oceanic phase (El Niño) accompanies high air surface pressure in the western Pacific and the cold phase (La Niña) accompanies low air surface pressure in the western Pacific (Trenberth et al., 2007). Generally, it has proved difficult to define an El Niño/La Niña event and there is no universal single definition (Trenberth and Hoar, 1997; Anthony and Stewart, 2001; Fu et al., 2007). In this study, the definition of Trenberth (1997) is adopted, namely that “... an El Niño can be said to occur if 5-month running means of sea temperature (SST) anomalies in the Niño 3.4 region $\left(5^{\circ} \mathrm{N}-5^{\circ} \mathrm{S}\right.$, $120^{\circ}-170^{\circ} \mathrm{W}$ ) exceed $0.4^{\circ} \mathrm{C}$ for 6 months or more". Similarly, La Niña, the opposite event to El Niño, can simply be said to occur if a 5-month running mean of SST anomalies falls below the threshold $-0.4{ }^{\circ} \mathrm{C}$ (See the upper panel in Fig. 2).

In this paper, the periods of El Niño events and La Niña events were used to stratify the precipitation and streamflow time series for analysing the influences of El Niño and La Niña on hydro-climatic variables in China. The precipitation/streamflow time series were first extracted for each calendar month conditioned by El Niño/La Niña events - for instance, the multi-year mean value of January precipitation occurs during El Niño periods was treated as "January precipitation in El Niño". Then, the sum of monthly precipitation from January to December in El Niño/La Niña months was treated as "annual" precipitation in El Niño/La Niña year (Fu et al., 2007).

\subsubsection{Precipitation/streamflow stratification according to the PDO cool/warm phase}

The PDO is a pattern of Pacific climate variability that shifts phases usually on an at least 20-30-year inter-decadal timescale (Mantua et al., 1997). It is detected as warm/cool surface water in the Pacific Ocean (north of $20^{\circ} \mathrm{N}$ ) - during 

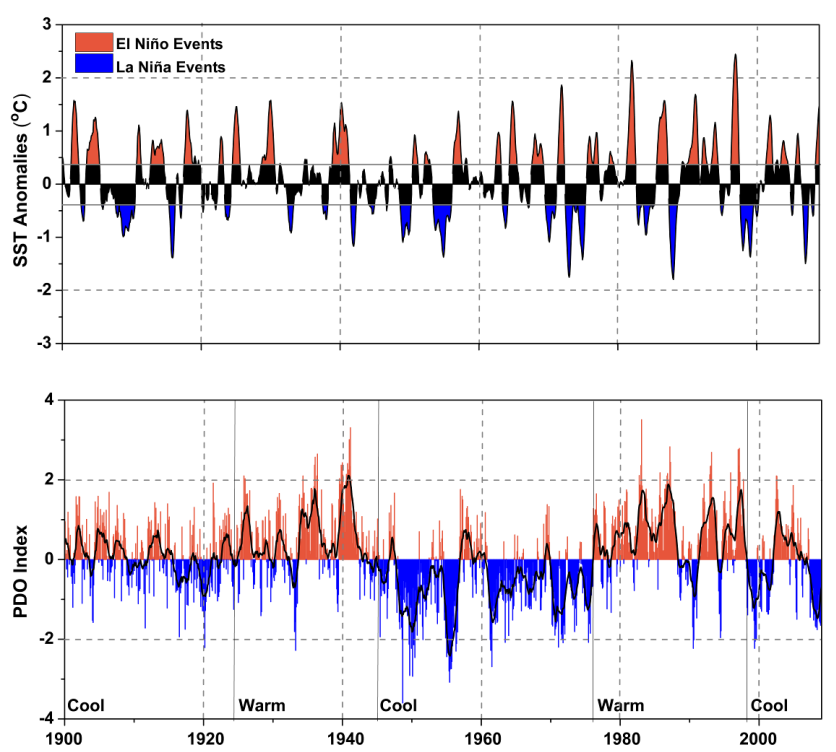

Figure 2. The definition of ENSO events (El Niño and La Niña) from 5-month running mean series of Niño 3.4 SST index (upper panel) and the partition of warm/cool phase PDO from monthly PDO index (lower panel).

a "warm" or "positive" phase, the west Pacific becomes cool and part of the eastern ocean warms while during a "cool" or "negative" phase, the opposite pattern occurs. The cool and warm PDO phases (Fig. 2) are identified from the PDO index series in accordance with the approach used in Mantua and Hare (2002) and Sen Roy (2011). Over the past century, the PDO was in a cool phase approximately during the periods 1901-1924, 1947-1976 and 1998-2009, and warm phase PDO regimes existed during the periods 1925-1946 and 1977-1997 (see lower panel in Fig. 2). It should be noted that these multi-decade epochs sometimes contain intervals of up to a few years in length in which the polarity of the PDO is reversed (e.g. the cool phase in 1998-2009 showed a warm phase in 2002-2005).

The precipitation/streamflow spanning the period 19012009 are stratified into two segments conditioned on the PDO warm/cool phase. Further, the series in Warm PDO-El Niño, Warm PDO-La Niña, Cool PDO-El Niño, and Cool PDOLa Niña are stratified using the method similar to Sect. 2.2.1 from the precipitation/streamflow series extracted for PDO warm/cool phase, separately. Additionally, Wilcoxon signedrank tests were adopted to determine whether average precipitation/streamflow received during Warm PDO/La Niña periods was statistically different from that received during Cool $\mathrm{PDO} / \mathrm{El}$ Niño periods at the 0.05 significance level. This is a nonparametric test equivalent to the dependent $t$ test, which does not assume normality in the data and can be used for cases when there are only a small number of samples available for analysis (Kolivras and Comrie, 2007).

\section{Results and discussion}

\subsection{Perspective impacts of ENSO on precipitation and streamflow over China}

\subsubsection{Precipitation impacts of El Niño and La Niña events}

Compared to the long-term average (1901-2009), the "annual" precipitation changes in El Niño and La Niña periods are spatially opposite (Fig. 3). For example, the overall "annual" precipitation increased in the North China Plain, Southwest China as well as the Tibetan Plateau while it declined in Northeast China, Southeast China and Northwest China during La Niña periods (Fig. 3). However, the trends in El Niño periods over these regions are clearly reversed. The Yangtze River can be spatially treated as a dividing line of ENSO influences on precipitation for eastern China, with the "annual" average precipitation obviously less (differences $<-5 \%$ ) in the southern regions of the Yangtze River and greater (differences $>5 \%$ ) in the northern regions (including the Yellow River, Hai River and Huai River) in La Niña periods than that in El Niño years. It should be noted that the results obtained in the Yellow River basin (similar to the North China Plain) are consistent with many previous studies (Gong and Wang, 1999; Fu et al., 2007; Hao et al., 2008).

The influences of El Niño and La Niña on precipitation are found to have clear seasonal and monthly characteristics (Fig. 4). For instance, the ENSO impacts on precipitation in summer and autumn are more significant than in winter and spring, especially for September, October and November. Moreover, the precipitation in Southeast China (including lower parts of the Pearl River and Yangtze River) is relatively larger during El Niño winter and spring and lower during El Niño summer and autumn compared to that during the corresponding La Niña periods. A possible reason is that the southern coast of South China is always influenced by different anomalous circulation systems in wet and dry seasons (Wu et al., 2003). In addition, the percentage changes in wet season precipitation (June to September) between El Niño and La Niña periods are similar to those for "annual" precipitation, because more than $40 \%$ of the total annual precipitation falls in the summer (Zhang et al., 2009).

The influences of El Niño and La Niña events on precipitation are also unevenly spatially distributed and are different from month to month over all China (Fig. 4). Although monthly precipitation changes between two ENSO phases over the majority of regions are not statistically significant at the 0.05 level, some consistent and interesting results are still seen. The overall influences of El Niño and La Niña on precipitation are more significant in eastern and southern China rather than in western and northern China. Correspondingly, the ENSO influences become progressively weaker from Pearl River to Yangtze River to Yellow River 


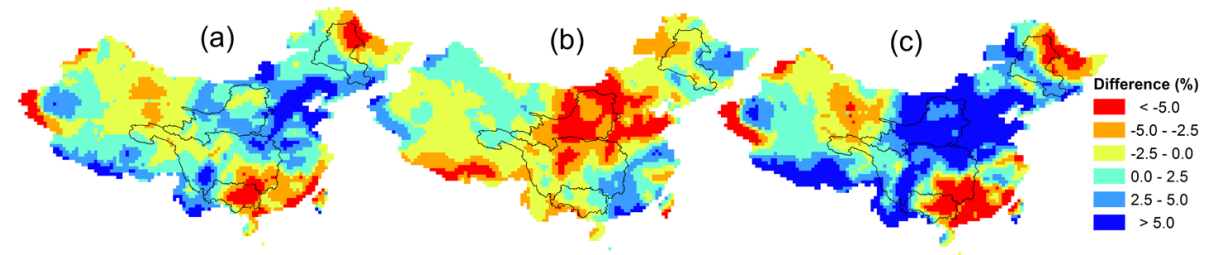

Figure 3. Percentage changes of annual precipitation in El Niño months and La Niña months over the long-term average (1901-2009): (a) annual precipitation in La Niña events; (b) annual precipitation in El Niño events; and (c) annual precipitation in La Niña events minus that in El Niño events.
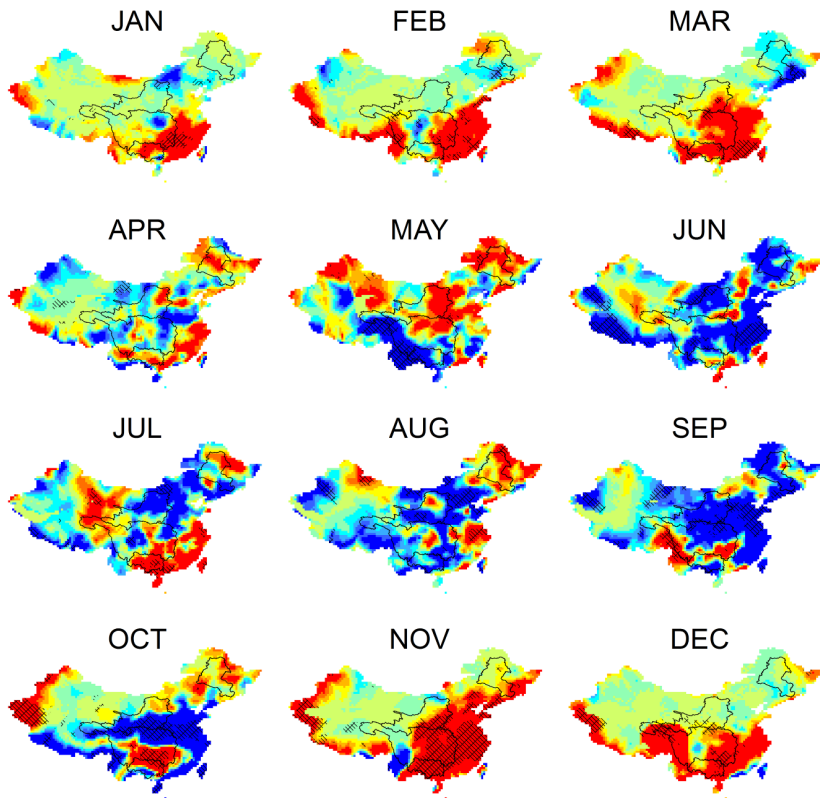

Difference (\%)

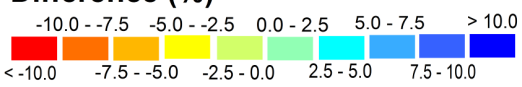

Figure 4. Monthly precipitation changes in La Niña months over China compared to El Niño months. Regions of change significant at the 0.05 level based on the Wilcoxon signed-rank test are shown with shadow.

and to Songhua River. A possible reason is that the eastern and southern portions of China received more total precipitation because they are near to the ocean and are significantly influenced by the East Asian monsoon and South Asian monsoon (Zhang et al., 1996). More specifically, the precipitation from November to March received from La Niña events is less than that received from El Niño events over almost all of China and the tendency is reversed in the remaining seven months, especially in the wet season (June-September). In October, the above trends are reversed in most parts of the Yellow River and Yangtze River.

In addition, precipitation pattern responses to El Niño/La Niña events show discrepancies among different parts of a basin. For example, the ENSO influences in the lower basin of the Songhua River are opposite to those in the head and middle basin. The different responses of the four river basins (or even for different parts of a basin) to ENSO are properly attributed to the spatially diverse influences of the different monsoon circulations and mid-latitudinal circulations. For example, the Pearl River basin is impacted by the retreating East Asian winter monsoon as well as the typhoon season, and the precipitation-streamflow regime in the subbasin is consequently considerably complex when responding to the ENSO influences (Jiang et al., 2007; Zhang et al., 2011). Moreover, Li et al. (2010) indicated that the East Asia summer monsoon exhibited a southward shift in its major components due to the meridional asymmetric warming, which would weaken the influences of the East Asian summer monsoon on Songhua River basin and result in a difference in ENSO responses between Songhua River basin and the other three basins.

\subsubsection{Streamflow impacts of El Niño and La Niña events}

The "annual" streamflow changes overall are greater in $\mathrm{La}$ Niña periods relative to El Niño periods for all four basins, especially for the Yellow River basin (Fig. 5). Moreover, the ENSO influence on streamflow is spatially and temporally consistent with that on precipitation for the major river basins over China with clear differences among months and basins. On the whole, the streamflow in the Yellow River basin, Yangtze River basin and Pearl River basin are more significantly influenced by El Niño and La Niña events compared to those in the Songhua River basin - especially in October and November. The streamflows in Songhua River basin for all twelve months in La Niña periods consistently increase while those in the majority months ( 8 of the 12) in El Niño periods decrease compared to multi-year average monthly streamflow during the past 100 years - only La Niña impacts in August are statistically significant. The monthly streamflow trends influenced by El Niño/La Niña events in the Yellow River basin are basically coincident with precipitation, with a relatively lower than normal amount in El Niño periods and a higher amount in La Niña periods for almost all months, but the statistical significance tests do not show clear seasonal characteristics (Fig. 5). The overall percentage difference between El Niño-related and La Niña-related streamflow is $32.1 \%$, and varies monthly from $10.1 \%$ (March) to $59.7 \%$ 


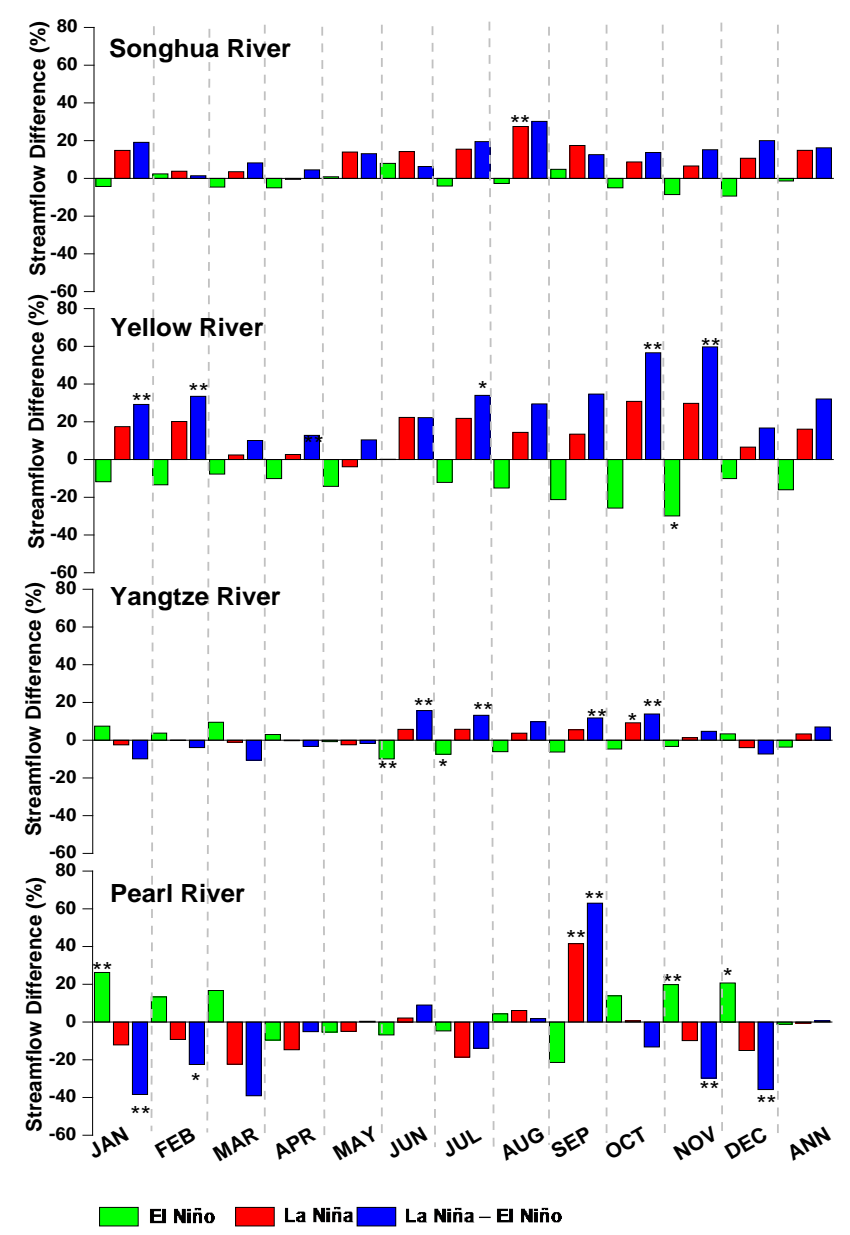

Figure 5. Monthly and annual streamflow changes over four major river basins in China in El Niño and La Niña months over the monthly/annual long-term average (1901-2004). The asterisks indicate the statistical significance based on Wilcoxon signed-rank test (** lower than $0.05,{ }^{*}$ lower than 0.10 , otherwise nothing). Note that the monthly streamflow changes in the Yellow River basin and Pearl River basin were only calculated during the period 1950-2004 due to limited availability of monthly streamflow data.

(November) (Fig. 5). The streamflow in January, February, April, July, October and November changes significantly between El Niño and La Niña events. Moreover, the percentage changes of monthly streamflow are relatively smaller in spring (March-May) during La Niña periods and larger in other seasons (especially in autumn), consistent with $\mathrm{Fu}$ et al. (2007) and Lü et al. (2011).

The significant influences of ENSO on streamflow in the Yangtze River mainly occur in summer and autumn while they primarily occur in winter and spring in the Pearl River. The spatial variability of streamflow is responsible for both the influences of El Niño mature phase on precipitation in summer when the intensified western Pacific subtropical high covers the southeastern periphery of China and the weakening of the Indian monsoon which provides less moisture inflow to the northern part of China (Zhang et al., 1999). The streamflow responses to ENSO for Yangtze River basin (Hankou station) exhibit obvious seasonal variations (Fig. 5). For example, streamflow is relatively higher in El Niño periods than in La Niña periods in winter (December-February) and spring while the reverse is the case in summer and autumn (September-November). In particular, compared to corresponding average monthly streamflow, the differences of La Niña-related streamflow and El Niño-related streamflow change significantly in June-September. In the Pearl River basin (Wuzhou Station), ENSO impacts seem to be more complicated. The absolute percentage differences of streamflow between La Niña and El Niño periods are all more than $10 \%$ from October to March, as well as in July. In September, the streamflow in La Niña month exceeds that in El Niño month and the percentage difference exceeds $63.0 \%$. Different to the Yangtze River basin, the ENSO influences in the Pearl River are only statistically significant $(0.05$ level $)$ on autumn and winter streamflow, possibly because of the Pearl River region location in tandem with the strengthening and weakening of sea surface temperature (SST) in the western Pacific (Juneng and Tangang, 2005).

\subsection{Perspective impacts of PDO on precipitation and streamflow}

\subsubsection{Variability of precipitation due to PDO impacts}

The percentage changes of "annual" precipitation also show spatially opposite responses to the PDO warm phase and cool phase, although only changes in a few regions are statistically significant at the 0.05 level (Fig. 6). Specifically, the "annual" precipitation in most parts of Northeast China and Northwest China tends to be higher during the PDO warm phase relative to that in the cool phase, especially in the Songhua River basin and in the inland watersheds of the Yellow River (blue regions in Fig. 6b). The results obtained are consistent with Zhu and Yang (2003), who indicate that summer precipitation (accounting for more than $50 \%$ of total annual precipitation) in Northeast and Northwest China increases during a warm PDO phase due to the weakening of the East Asian summer monsoon and the southward shift of the Western Pacific Subtropical High. In contrast, the "annual" streamflow responses are opposite over the North China Plain, southwest China and Central China, with precipitation less during the warm PDO phase and more during the cool phase (Yang et al., 2005; Fu et al., 2009). The results in northern China areas may be because they always dominated by high pressure and experience precipitation decrease when the Pacific is in a warm phase, with the sea temperature over the tropical mideastern Pacific rising and that over the central part of northern Pacific lower than normal (Yang et al., 2005). Additionally, precipitation over the Yellow River basin (Fu et al., 2004), Yangtze River basin and Pearl River basin decreases from the mid- and late 1970s to the 1990s when the PDO is 


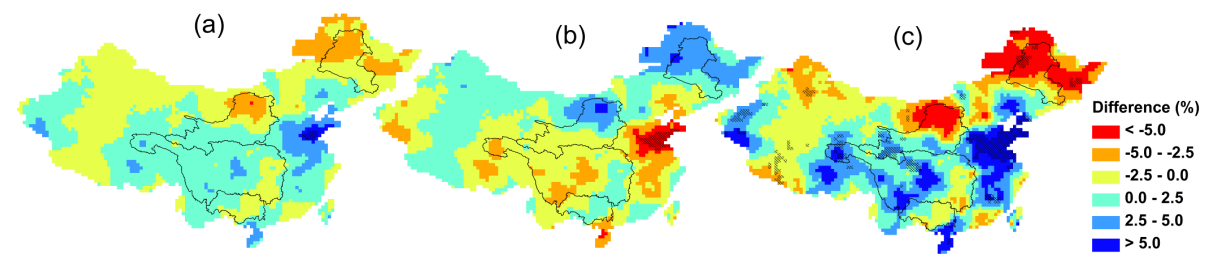

Figure 6. Percentage changes of annual precipitation in PDO warm phase and cool phase over the long-term average (1901-2009): (a) annual precipitation in POD cool phase; (b) annual precipitation in POD warm phase; (c) annual precipitation in POD cool phase minus that in POD warm phase. Regions of change significant at the 0.05 level based on the Wilcoxon signed-rank test are shown with shadow.

in a persistent warming phase, and then increases after 2000 when the PDO entered an unstable cool phase.

\subsubsection{Variability of streamflow due to PDO impacts}

The "annual" streamflow changes against the long-term average shown in Fig. 7 are basically consistent with those for precipitation during warm and cool PDO phases, although there are no significant trends tested. The PDO influences in Songhua River basin are opposite to those in the other three basins with the streamflow clearly higher than the long-term average $(6.1 \%)$ in the PDO warm phase and lower in the PDO cool phase $(-4.0 \%)$. The streamflow changes related to the PDO warm/cool phase correspond to the variability of streamflow dry/wet stages: 1900-1907, 1915-1928, 19751980 and 1999-2005 are four dry stages, 1970-1974 is a medium-water stage and 1908-1914, 1929-1969 and 19811998 are three wet stages (Song et al., 2010). Instead, in the Yellow River, Yangtze River and Pearl River, the streamflow is relatively lower in the PDO warm phase and higher in the PDO cool phase and the percentage differences become progressively smaller from north to south. The results are consistent with Gordon and Giulivi (2004), indicating that the high (low) runoff in the Yangtze River and Yellow River correspond to the PDO negative (positive) phase. Additionally, similar results are found when replacing the 100-year streamflow observations by the 50 -year set to analyse the connections between streamflow and PDO in Songhua River and Yangtze River (not shown). It should be noted that the gradually decreased streamflow tendency in the downstream Yellow River in the PDO cool phase after 2000 may be due to the human activities (Ren et al., 2002), for example, water withdrawal contributed more than $60 \%$ of the streamflow decrease in the downstream Yellow River after 2000 (Zhang et al., 2011).

\subsection{Combined influences of ENSO and PDO on both streamflow and precipitation}

There is much evidence (Chan and Zhou, 2005; Andreoli and Kayano, 2005) to indicate that the PDO coupled with ENSO affects precipitation constructively (strong and welldefined anomalies) when they are in phase and destructively (weak and noisy anomalies) when they are out of phase. In

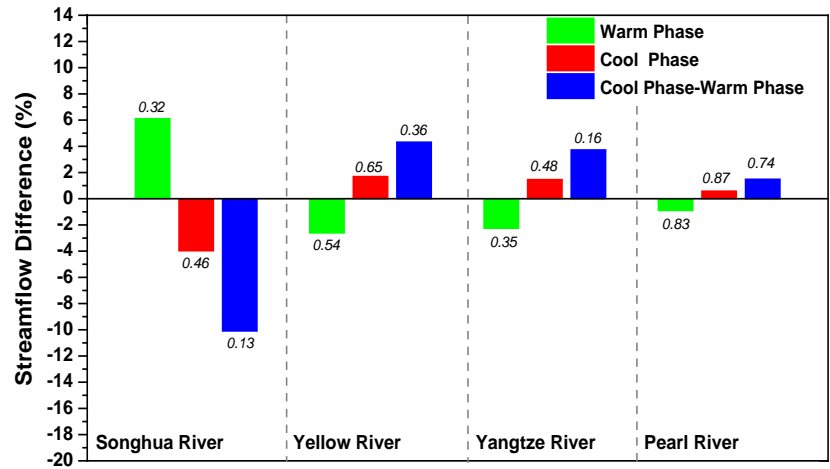

Figure 7. Percentage changes of annual streamflow over four major river basins in China in PDO warm phase and cool phase over the long-term average (1901-2009); $p$ values based on Wilcoxon signed-rank test are shown on the top/bottom of each bar.

this study, the precipitation/streamflow in El Niño periods are compared to those in La Niña periods during the PDO warm/cool phase, respectively (Figs. 8 and 9). Results show that the "annual" precipitation changes in El Niño/La Niña period compared to multi-year average in cool PDO phase are similar to Fig. 3, which indicates that the cool PDO phase does not significantly modulate the ENSO influence on precipitation. However, in the warm PDO phase, the percentage changes for the precipitation are clearly related to El Niño/La Niña. For instance, in Northeast China and Northwest China, the precipitation in La Niña periods is obviously higher than that in El Niño periods during PDO warm phase while the reverse is the case during PDO cool phase. However, the precipitation responses to the two PDO phases are almost opposite in South China and Central China, including most parts of the Yangtze River basin and the upper stream of the Pearl River basin.

El Niño/La Niña-related streamflows in the four basins show different responses during different PDO phases (Fig. 9). During the PDO cool phase, the streamflows in all basins tend to be higher in La Niña periods and lower in El Niño periods. The results obtained are similar to the single impacts of El Niño/La Niña shown in Fig. 5, which indicate that cool PDO also do not obviously change El Niño/La Niña influences on streamflow anomalies. However, 


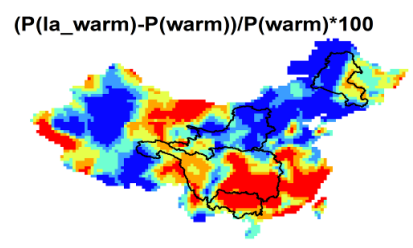

$\mathrm{P}\left(\mathrm{la} \_\right.$cool $)-\mathrm{P}(\mathrm{cool}) / \mathrm{P}(\mathrm{cool}) * 100$
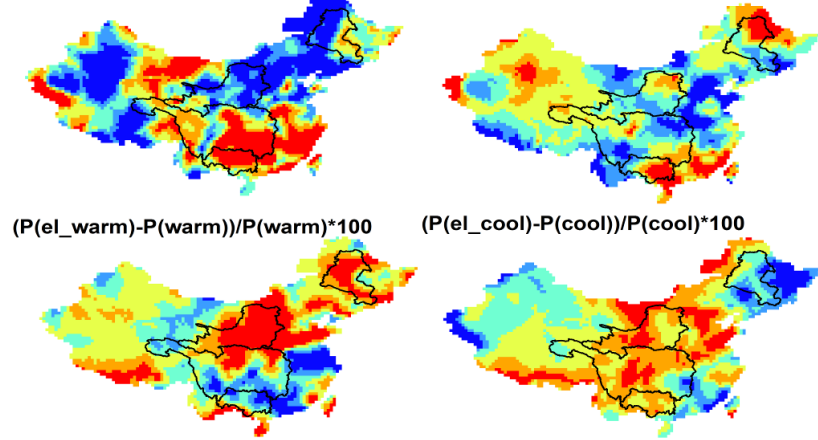

(P(el_cool) $-\mathrm{P}(\mathrm{cool})) / \mathrm{P}(\mathrm{cool}) * 100$

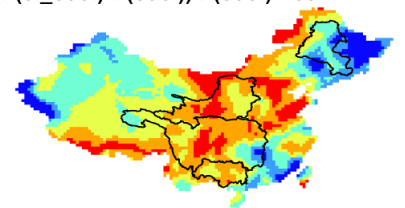

$\left(\mathrm{P}\left(\mathrm{la} \_w a r m\right)-\mathrm{P}\left(\mathrm{el} \_w a r m\right)\right) / \mathrm{P}(\text { warm })^{*} 100 \quad\left(\mathrm{P}\left(\mathrm{la} \_\right.\right.$cool $)-\mathrm{P}(\mathrm{el}$ _cool $\left.)\right) / \mathrm{P}(\mathrm{cool}) * 100$
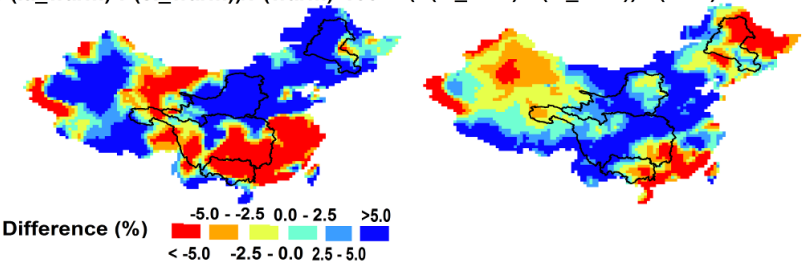

Figure 8. Percentage changes of precipitation between El Niño and La Niña periods during PDO warm phase (left panel) and PDO cool phase (right panel).

the cool PDO phase still causes both more negative anomalies in El Niño-related streamflow and more positive anomalies in La Niña-related streamflow in South China (including most parts of the Yangtze River basin and the Pearl River basin) and induces both fewer negative anomalies in El Niño-related streamflow and fewer positive anomalies in La Niña-related streamflow in the Northern China (including the Songhua River basin and the Yellow River basin). Moreover, it should also be noted that the streamflow and precipitation responses to El Niño/La Niña are opposite during the PDO cool phase in the Songhua River basin, which may be because the Harbin Station is located midway on the stream and cannot fully represent the entire basin.

During the PDO warm phase, the streamflow in La Niña periods is relatively higher than that in El Niño periods in Songhua River basin and Yellow River basin with change percentages $9.7 \%$ and $44.1 \%$, respectively. Clearly, the warm PDO enhances the anomalies in both basins during La Niña and El Niño periods. However, the situation is different in southern China. For example, fewer differences between El Niño-related and La Niña-related streamflow in the Yangtze River basin are found, with overall percentage change of only $0.7 \%$, which indicates that compared to the cool PDO phase, the warm PDO phase weakens the ENSO influences in the Yangtze River basin. In the Pearl River basin, La Niñarelated streamflow tends to be lower than El Niño-related streamflow with a percentage difference of $-21.8 \%$. In addition, compared to the percentage changes in the PDO cool phase $(10 \%)$ and in the long-term average without considering the impacts of PDO $(0.6 \%)$, the warm PDO is seen to

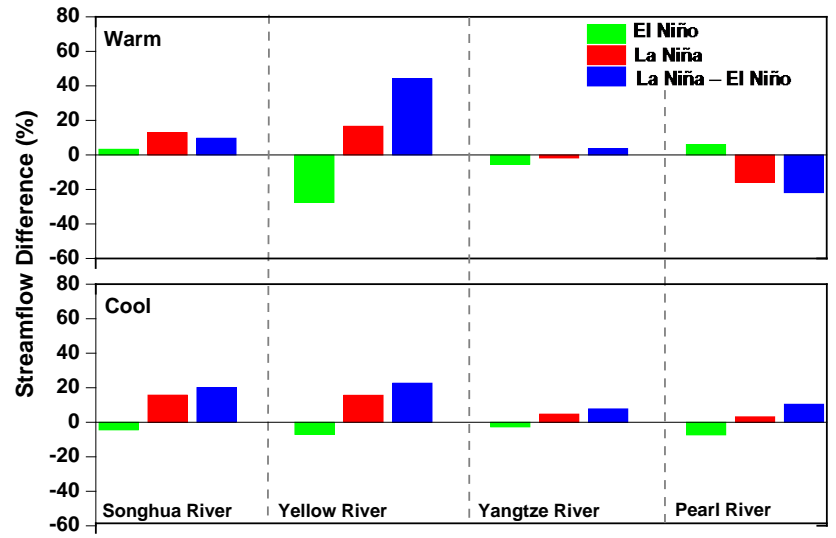

Figure 9. Percentage changes of streamflow between El Niño and La Niña periods during the PDO warm phase (upper panel) and the PDO cool phase (lower panel).

increase El Niño-related streamflow and decrease La Niñarelated streamflow. In other words, similar to Andreoli and Kayano (2005), the warm PDO acts as constructive influence in North China and destructive influence in South China. Overall, El Niño/La Niña-related precipitation/streamflow experience similar variability during the warm/cool PDO phase except for the Songhua River basin in the cool PDO phase. Moreover, streamflow, which is also influenced by many other factors such as global SST, long-wave radiation, snow and human activities (Xu et al., 2007), seems to be more sensitive than precipitation during El Niño/La Niña periods in both warm and cool PDO phases (Fig. 9). However, the general influence patterns of the combined effects are basically consistent. Compared to the ENSO impacts, although the PDO indicator does not show significant prediction capacity for annual streamflow, probably because of its multi-decadal cycles, its modulation effects on ENSO still deserve to be included in research when considering the long-term influences of ENSO on annual/seasonal/monthly water resources.

\section{Summary and conclusions}

This study has investigated the single and combined impacts of ENSO and PDO on the precipitation/streamflow over China during the last century, to enrich our knowledge for understanding their complex spatial-temporal teleconnections and provide a scientific basis for water resource prediction using ENSO/PDO as a potential predictor. The following conclusions can be drawn.

Overall, El Niño events mainly decrease while La Niña events increase the precipitation/streamflow over China. However, considerable differences exist among months and basins - for example, the precipitation/streamflow changes in the Yellow River basin, Yangtze River basin and Pearl River basin are more significantly influenced by El Niño 
and La Niña events compared to those in the Songhua River basin among different months - probably because precipitation/streamflow in regions/basins close to the ocean are more significantly influenced due to the mixed impact of ENSO and other factors such as the East Asian monsoon, South Asian monsoon and typhoon systems. Additionally, due to the influences of different circulation systems (Wu et al., 2003), the significant influence of ENSO on streamflow in the Yangtze River mainly occurs in summer and autumn while that in the Pearl River primarily occurs in winter and spring.

Although significant changes are rarely detected, the influences of the PDO warm/cool phases on precipitation/streamflow are basically similar as but less than that of El Niño/La Niña. The precipitation/streamflow in the Songhua River basin and most parts of the Yellow River basin are relatively larger during the warm PDO phase than during the cool PDO phase, while in the Pearl River basin and most parts of Northwest China these responses are reversed. When considering both the influences of the PDO and ENSO, the responses for precipitation/streamflow are shown to be opposite in northern China and southern China. El Niño-related precipitation/streamflow decreases while La Niña-related precipitation/streamflow increases during the PDO warm phase in northern China (including the Songhua River basin and Yellow River basin), and the cool PDO phase does not obviously change El Niño/La Niña influences on positive-negative streamflow anomalies.

The variability of streamflow corresponding to ENSO/PDO is roughly consistent with that of precipitation on the annual scale. On the seasonal/monthly scale, its response seems more complex than that of precipitation. Clearly, streamflow is also affected by other factors such as human activities and land use changes. However, ENSO and PDO still showed a significant influence on the observed streamflow in all four major basins in China. The results obtained indicate that monthly/seasonal ENSO could be a potential predictor for streamflow prediction in the Yangtze River, Pearl River or even for the Yellow River; however, further research on the physical mechanism driving these relations is needed. Firstly, the influences should be further quantitatively assessed to enhance the forecast abilities of the ENSO/PDO indicator for streamflow and water resource modelling and forecasting. Additionally, other factors influencing the streamflow should be comprehensively considered in future studies, such as the East Asia summer monsoon (Wu and Wang, 2002), global SST, outgoing long-wave radiation, sea level pressure, snow and human activities (Xu et al., 2007). Finally, ENSO/PDO events can be predicted 1-2 years in advance using physically based coupled ocean-atmosphere models (Lü et al., 2011), and the potential future states and influences of ENSO/PDO could be further assessed by considering as far as possible the aforementioned factors by coupling atmospheric/oceanic/land surface models with a proper distributed physical-based hydrological model.

Acknowledgements. This study is financially supported by the National Natural Science Foundation for Young Scholar of China (41101030), Postdoctoral Science Foundation of China (20100480443, 201104141 and 2014M550850), the National Basic Research Program of China (2010CB428406), Strategic Priority Research Program of the Chinese Academy of Sciences (XDA05090309) and the Australia 2012 Endeavour Award. The third author (Guobin Fu) is supported by the "Australia China Research Centre on River Basin Management". We wish to thank the editor and all anonymous reviewers for their invaluable comments and constructive suggestions using to improve the quality of the manuscript.

Edited by: S. Uhlenbrook

\section{References}

Andreoli, R. V. and Kayano, M. T.: ENSO-related rainfall anomalies in South America and associated circulation features during warm and cold Pacific decadal oscillation regimes, Int. J. Climatol., 25, 2017-2030,2005.

Anthony, S. and Stewart, W. F.: On the identification of ENSOinduced rainfall and runoff variability: a comparison of methods and indices, Hydrolog. Sci. J., 46, 715-727, 2001.

Barnett, T. P., Pierce, D. W., Latif, M., Dommenget, D., and Saravanan, R.: Interdecadal interactions between the tropics and midlatitudes in the Pacific basin, Geophys. Res. Lett., 26, 615-618, 1999.

Cayan, D. R., Dettinger, M. D., Diaz, H. F., and Graham, N. E.: Decadal variability of precipitation over western North America, J. Climate, 11, 3148-3166, 1998.

Chan, J. C. L. and Zhou, W.: PDO, ENSO and early summer monsoon rainfall over south China, Geophys. Res. Lett., 32, L08810, doi:10.1029/2004GL022015, 2005.

Chen, Y. N. and Xu, Z. X.: Plausible impact of global climate change on water resources in the Tarim River Basin, Sci. China Ser. D, 48, 65-73, 2005.

Fu, G. B., Chen, S. L., Liu, C. M., and Shepard, D.: Hydro-climatic trends of the Yellow River basin for the last 50 years, Climatic Change, 65, 149-178, 2004.

Fu, G. B., Charles, S. P., Viney, N. R., Chen, S. L., and Wu, J. Q.: Impacts of climate variability on stream-flow in the Yellow River, Hydrol. Process., 21, 3431-3439, 2007.

Fu, G. B., Charles, S. P., Yu, J. J., and Liu, C. M.: Decadal climatic variability, trends, and future scenarios for the North China Plain, J. Climate, 22, 2111-2123, 2009.

Gong, D. Y. and Wang, S. W.: Impacts of ENSO on rainfall of global land and China, Chinese Sci.Bull., 44, 852-857, 1999.

Gordon, A. L. and Giulivi, C. F.: Pacific decadal oscillation and sea level in the Japan/East sea, Deep-Sea Res. Pt. I, 51, 653-663, 2004.

Hao, Z. X., Zheng, J. Y., and Ge, Q. S.: Precipitation cycles in the middle and lower reaches of the Yellow River (1736-2000), J. Geogr. Sci., 18, 17-25, 2008. 
Higins, R. W. and Shi, W.: Dominant factors responsible for interannual variability of the summer monsoon in the south-western United States, J. Climate, 13, 759-775, 2000.

Huang, R. H. and Wu, Y. F.: The influence of ENSO on the summer climate change in China and its mechanism, Adv. Atmos. Sci., 6, 21-32, 1989.

Jiang, T., Su, B. D., and Hartmann, H.: Temporal and spatial trends of precipitation and river flow in the Yangtze River Basin, 19612000, Geomorphology, 85, 143-154, 2007.

Juneng, L. and Tangang, F. T.: Evolution of ENSO-related rainfall anomalies in Southeast Asia region and its relationship with atmosphere-ocean variations in Indo-Pacific sector, Clim. Dynam., 25, 337-350, 2005.

Kolivras, K. N. and Comrie, A. C.: Regionalization and variability of precipitation in Hawaii, Phys. Geogr., 28, 76-96, 2007.

Krishnan, R. and Sugi, M.: Pacific decadal oscillation and variability of the Indian summer monsoon rainfall, Clim. Dynam., 21, 233-242, 2003.

Latif, M. and Barnett, T. P.: Decadal climate variability over the North Pacific and North America: Dynamics and predictability, J. Climate, 9, 2407-2423, 1996.

Li, C. Y.: Interaction between anomalous winter monsoon in East Asia and El Nino events, Adv. Atmos. Sci., 7, 36-46, 1990.

Li, J. P., Wu, Z. W., Jiang, Z. H., and He, J. H.: Can global warming strengthen the East Asian Summer Monsoon?, J. Climate, 23, 6696-6705, 2010.

Li, Q., Yang, S., Kousky, V. E., Higgins, R. W., Lau, K.-M., and Xie, P.: Features of Cross-Pacific climate shown in the variability of China and US precipitation, Int. J. Climatol., 25, 1675-1696, 2005.

Liang, K., Bai, P., Li, J. J., and Liu, C. M.: Variability of temperature extreme in the Yellow River basin during 1961-2011, Quatern. Int., 336, 52-64, 2014.

Liu, Y. Q. and Ding, Y. H.: Reappraisal of the influence of ENSO events on seasonal precipitation and temperature in China, Sci. Atmos. Sin., 19, 200-208, 1995.

Lü, A., Jia, S., Zhu, W., Yan, H., Duan, S., and Yao, Z.: El NiñoSouthern Oscillation and water resources in the headwaters region of the Yellow River: links and potential for forecasting, Hydrol. Earth Syst. Sci., 15, 1273-1281, doi:10.5194/hess-15-12732011, 2011.

Ma, Z. G. and Shao, L. J.: Relationship between dry/wet variation and the Pacific Decade Oscillation (PDO) in northern China during the last 100 years, Chin. J. Atmos. Sci., 30, 464-474, 2006.

Mantua, N. J. and Hare, S. R.: The Pacific decadal oscillation, J. Oceargr., 58, 35-44, 2002.

Mantua, N. J., Hare, S. R., Zhang, Y., Wallace, J. M., and Francis, R. C.: A Pacific interdecadal climate oscillation with impacts on salmon production, B. Am. Meteorol. Soc., 78, 1069-1080, 1997.

Minobe, S.: Spatio-temporal structure of the pentadecadal variability over the North Pacific, Prog. Oceanogr., 47, 381-408, 2000.

Mitchell, T. D. and Jones, P. D.: An improved method of constructing a database of monthly climate observations and associated high-resolution grids, Int. J. Climatol., 25, 693-712, 2005.

Neal, E., Todd Walter, M., and Coffeen, C.: Linking the pacific decadal oscillation to seasonal stream discharge patterns in Southeast Alaska, J. Hydrol., 263, 188-197, 2002.
Nigam, S., Barlow, M., and Berbery, E. H.: Analysis links Pacific decadal variability to drought and streamflow in the United States, EOS T. Am. Geophys. Un., 80, 621-625, 1999.

Ren, L. L., Wang, M. R., Li, C. H., and Zhang, W.: Impacts of human activitiy on river runoff in the northern area of China, J. Hydrol., 261, 204-217, 2002.

Sen Roy, S.: Identification of periodicity in the relationship between PDO, El Niño and peak monsoon rainfall in India using S-transform analysis, Int. J. Climatol., 31, 1507-1517, 2011.

Sen Roy, S. and Sen Roy, N.: Influence of Pacific decadal oscillation and El Niño Southern oscillation on the summer monsoon precipitation in Myanmar, Int. J. Climatol., 31, 14-21, 2011.

Silva, G. A. M., Drumond, A., and Ambrizzi, T.: The impact of El Niño on South American summer climate during different phases of the Pacific Decadal Oscillation, Theor. Appl. Climatol., 106, 307-319, 2011.

Song, X., Mu, X., Gao, P., Wang, F., and Wang, S.: Analysis on historical evolution and driving force of rainfall and runoff of Harbin Station in Songhua River, Sci. Soil Water Conserv., 8, 46-51, 2010.

Trenberth, K. E.: The Definition of El Niño, B. Am. Meteorol. Soc., 78, 2771-2777, 1997.

Trenberth, K. E. and Hoar, T. J.: El Niño and climate change, Geophys. Res. Lett., 24, 3057-3060, 1997.

Trenberth, K. E., Jones, P. D., Ambenje, P., Bojariu, R., Easterling, D., Tank Klein, A., Parker, D., Rahimzadeh, F., Renwick, J. A., Rusticucci, M., Soden, B., and Zhai, P. M.: Observations: Surface and Atmospheric Climate Change, in: Climate Change 2007: The Physical Science Basis.Contribution of Working Group I to the Fourth Assessment Report of the Intergovernmental Panel on Climate Change, edited by: Solomon, S., Qin, D., Manning, M., Chedvn, Z., Marquis, M., Averyt, K. B., Tignor, M., and Miller, H. L., Cambridge University Press, Cambridge, UK, 235-336, 2007.

Verdon, D. C., Wyatt, A. M., Kiem, A. S., and Franks, S. W.: Multidecadal variability of rainfall and streamflow: Eastern Australia, Water Resour. Res., 40, W10201, doi:10.1029/2004WR003234, 2004.

Wang, L., Chen, W., and Huang, R. H.: Interdecadal modulation of PDO on the impact of ENSO on the east Asian winter monsoon, Geophys. Res. Lett., 35, L20702, doi:10.1029/2008GL035287, 2008.

Wen, C., Graf, H. F., and Huang, R. H.: The interannual variability of East Asian winter monsoon and its relation to the summer monsoon, Adv. Atmos. Sci., 17, 48-60, 2000.

Wu, R., Hu, Z. Z., and Kirtman, B. P.: Evolution of ENSO-related rainfall anomalies in East Asia, J. Climate, 16, 3742-3758, 2003.

$\mathrm{Wu}, \mathrm{R}$. G. and Wang, B.: A contrast of the East Asian Summer Monsoon-ENSO relationship between 1962-77 and 1978-93, J. Climate, 15, 3266-3279, 2002.

Xu, K. Q., Brown, C., Kwon, H., Lall, U., Zhang, J. Q., Hayashi, S., and Chen, Z. Y.: Climate teleconnections to Yangtze river seasonal streamflow at the Three Gorges Dam, China, Int. J. Climatol., 27, 771-780, 2007.

Xu, Z. X., Takeuchi, K., and Ishidaira, H.: Correlation between El Nino Southern Oscillation (ENSO) and precipitation in Southeast Asia and the Pacific region, Hydrol. Process., 18, 107-123, 2004. 
Yang, X. Q., Xie, Q., Zhu, Y. M., Sun, X. Q., and Guo, Y. J.: Decadal-to-interdecadal variability of precipitation in North China and associated atmospheric and oceanic anomaly patterns, Chin. J. Geophys., 48, 789-797, 2005.

Zhang, Q., Xu, C. Y., Jiang, T., and Wu, Y. J.: Possible influence of ENSO on annual maximum streamflow of the Yangtze River, China, J. Hydrol., 333, 265-274, 2007.

Zhang, Q., Xu, C. Y., Zhang, Z., Chen, Y. D., and Liu, C. L.: Spatial and temporal variability of precipitation over China, 1951-2005, Theor. Appl. Climatol., 95, 53-68, 2009.

Zhang, Q., Singh, V. P., Sun, P., Chen, X., Zhang, Z. X., and Li, J. F.: Precipitation and streamflow changes in China: Changing patterns, causes and implications, J. Hydrol., 401, 204-216, 2011.
Zhang, R., Sumi, A., and Kimoto, M.: Impact of El Niño on the East Asian monsoon: A diagnostic study of the '86/87 and '91/92 events, J. Meteorol. Soc. Jpn., 74, 49-62, 1996.

Zhang, R., Sumi, A., and Kimoto, M.: A diagnostic study of the impact of El Nino on the precipitation in China, Adv. Atmos. Sci., 16, 229-241, 1999.

Zhou, L. T. and Wu, R. G.: Respective impacts of the East Asian winter monsoon and ENSO on winter rainfall in China, J. Geophys. Res., 115, D02107, doi:10.1029/2009JD012502, 2010.

Zhu, Y. M. and Yang, X. Q.: Relationships between Pacific Decadal Oscillation (PDO) and climate variabilities in China, Acta Meteorol. Sin., 61, 641-654, 2003. 